\title{
Differential Effects of Amphetamines-Induced Neurotoxicity on Appetitive and Aversive Pavlovian Conditioning in Mice
}

\author{
Cindy Achat-Mendes', Syed F Ali ${ }^{2}$ and Yossef Itzhak*,I \\ 'Neuroscience Program and Department of Psychiatry \& Behavioral Sciences (R-629), University of Miami School of Medicine, Miami, FL, USA; \\ ${ }^{2}$ Division of Neurotoxicology, NCTR/FDA, Jefferson, AR, USA
}

\begin{abstract}
The abuse of substituted amphetamines such as methamphetamine (METH) and 3,4-methylenedioxymethamphetamine (MDMA/ Ecstasy) can result in neurotoxicity, manifested as the depletion of dopamine (DA) and 5-hydroxytriptamine (5-HT; serotonin) axon terminal markers in humans and animal models. Human METH and MDMA users exhibit impairments in memory and executive functions, which may be a direct consequence of the neurotoxic potential of amphetamines. The objective of this study was to investigate the influence of amphetamines-induced neurotoxicity on Pavlovian learning. Using mouse models of selective DA neurotoxicity (METH; $5 \mathrm{mg} / \mathrm{kg} \times 3$ ), selective $5-\mathrm{HT}$ neurotoxicity (fenfluramine /FEN; $25 \mathrm{mg} / \mathrm{kg} \times 4$ ) and dual DA and 5-HT neurotoxicity (MDMA; I5 mg/ $\mathrm{kg} \times 4$ ), appetitive and aversive conditioning were investigated. Dopaminergic neurotoxicity significantly impaired METH and cocaine conditioned place preference (CPP), but had no effect on LiCl-induced conditioned place aversion (CPA). In contrast, serotonergic neurotoxicity significantly enhanced CPP, and had no effect on CPA. Dual dopaminergic/serotonergic neurotoxicity had no apparent effect on CPP; however, CPA was significantly attenuated. Postmortem analysis revealed that significantly diminished levels of DA and 5 HT markers persisted in the striatum, frontal cortex, hippocampus, and amygdala. These findings suggest that amphetamines-induced dopaminergic and serotonergic neurotoxicity exert opposing influences on the affective state produced by subsequent drug reward, while dual dopaminergic/serotonergic neurotoxicity impairs associative learning of aversive conditioning. Furthermore, results revealed that amphetamines-induced DA and 5-HT neurotoxicity modulates appetitive Pavlovian conditioning similar to other DA and 5-HT neurotoxins. Modulation of Pavlovian conditioning by amphetamines-induced neurotoxicity may be relevant to compulsive drug-seeking behavior in METH and MDMA abusers.

Neuropsychopharmacology (2005) 30, I I28- I I37, advance online publication, 26 January 2005; doi: 10.1038/sj.npp. 1300675
\end{abstract}

Keywords: conditioned place preference (CPP); conditioned place aversion (CPA); dopamine; serotonin; associative learning; psychostimulants

\section{INTRODUCTION}

Abuse of the amphetamine derivatives, methamphetamine (METH) and 3,4-methylenedioxymethamphetamine (MDMA/Ecstasy), is steadily increasing in the US (Gibson et al, 2002; Freese et al, 2002; Strote et al, 2002). The deleterious effect of METH abuse has been described as dopamine (DA) neurotoxicity, that is, degeneration of DA nerve terminals and consequent depletion of DA, tyrosine hydroxylase, and DA transporters (DAT) (Davidson et al, 2001; Seiden and Sabol, 1996; Volkow et al, 2001a). In

\footnotetext{
*Correspondence: Dr Y Itzhak, Department of Psychiatry and Behavioral Sciences (R-629), Gautier Building Room \#503, I0II NW 15th Street, University of Miami School of Medicine, Miami, FL 33136, USA, Tel: + 305243 4635, Fax: + 3052432989 ,

E-mail: yitzhak@med.miami.edu

Received 3 November 2004; revised 10 December 2004; accepted 12 December 2004

Online publication 17 December 2004 at http://www.acnp.org/ citations/NPP I 2 | 7040405 I 5/default.pdf
}

humans, METH-induced DA neurotoxicity is concurrent with impairments in recall memory (Chang et al, 2002; Simon et al, 2000; Thompson et al, 2004), and higher executive functions of the prefrontal cortex, such as decision-making (Rogers et al, 1999). In rats, exposure to moderate (Vorhees et al, 2000) and neurotoxic (Friedman et al, 1998) doses of METH disturbed spatial learning in the Morris water maze and the radial arm maze (Chapman et al, 2001). Similarly, extensive exposure to MDMA produces serotonergic neurotoxicity, that is, significant reduction of serotonin (5-hydroxytriptamine, 5-HT) and 5-HT transporters (5-HTT) in rats (Lyles and Cadet, 2003) and humans (McCann et al, 1998; Semple et al, 1999). In human MDMA users, poor performance in memory tests (Bhattachary and Powell, 2001; Bolla et al, 1998; Gouzoulis-Mayfrank et al, 2003; Parrott et al, 1998) and tasks requiring complex attention (McCann et al 1999; Verkes et al, 2001) was correlated with heavy patterns of MDMA abuse and subsequent 5-HT deficits. Importantly, while the neurotoxic effects on DA and 5-HT neurons may be reversible, the 
consequences of METH and MDMA on cognitive function appear to be long lasting, such that in humans, both abstinent (Bolla et al, 1998; Reneman et al, 2001; Volkow et al, 2001b) and current users show significant memory impairments. This suggests that amphetamines-induced neurotoxicity generates long-lasting neural adaptations that influence cognition. There are scant and conflicting reports on the effects of MDMA-induced neurotoxicity on learning and memory in rodents and non-human primates. Marston et al (1999) reported that MDMA neurotoxicity caused rats to exhibit deficits in working memory in the delayed nonmatch to place task and Taffe et al (2003) demonstrated that monkeys exposed to neurotoxic MDMA treatments performed lower in spatial working memory tests compared to controls. However, it was also reported that MDMA neurotoxicity in rats did not hinder spatial memory assessed by the place navigation learning-set task (Robinson et al, 1993) or short-term memory in the T-maze task (Ricaurte et al, 1993). Nevertheless, there is strong evidence that human METH and MDMA users exhibit cognitive deficits that are consistently associated with amphetaminesinduced damage to DA and 5-HT systems.

Studies on amphetamines-induced neurotoxicity have focused on working memory, higher executive processing (prefrontal cortex-dependent), and spatial learning (hippocampus-dependent). However, it is likely that other forms of learning and memory, which recruit additional neural substrates (eg amygdala), are affected by amphetaminesinduced neurotoxicity. Like the neurons of the prefrontal cortex and striatum, amygdala nuclei are innervated by DA and 5-HT systems and are thus potential sites for METH and MDMA neurotoxicity. Studies have demonstrated that lesions of amygdala nuclei and hippocampus interfere with the acquisition and expression of associative learning, as determined by Pavlovian conditioning experiments (Gallagher et al, 1990; Packard and McGaugh, 1996; Phillips and LeDoux, 1992). Pavlovian conditioning is accomplished by pairing a reward or punishment (unconditioned stimulus/ US) with a neutral context (conditioned stimulus/CS) such that the CS alone elicits conditioned response (CR) following US-CS pairing. Appetitive US produces approach behavior that is dependent on DA-mediated reward, whereas aversive US produces escape behavior that is independent of DA-mediated reward (Di Chiara, 2002; Isaac et al, 1989). Therefore, Pavlovian conditioning is achieved by (a) the affective state produced by the US and (b) learning and memory of the US-CS association. The influence of amphetamines-induced neurotoxicity on Pavlovian learning is not clear. Our previous study revealed that METH neurotoxicity diminished the development of conditioned place preference (CPP) response (Itzhak et al, 2002). This finding suggests that METH neurotoxicity can impair Pavlovian conditioning either via the affective state caused by the US (drug reward) and/or via the acquisition of the US-CS association.

The present study was undertaken to investigate the influence of amphetamines-induced neurotoxicity on two forms of Pavlovian conditioning: (a) appetitive conditioning (CPP) and (b) aversive conditioning (conditioned place aversion; CPA). We have previously shown that METH and FEN selectively deplete dopaminergic (Itzhak and Ali, 1996) and serotonergic (Itzhak et al, 2003b) markers, respectively, while MDMA reduces both DA and 5-HT markers in Swiss Webster mice (Itzhak et al, 2003a; Itzhak and AchatMendes, 2004). Using these mouse models, we investigated the effect of amphetamines-induced injury to individual monoamine systems on CPP and CPA. We reason that these studies are relevant to the functional consequences of METH and MDMA neurotoxicity on cognition and subsequent susceptibility to drug use in humans. Pavlovian conditioning is a model of incentive-based learning and memory and is thus relevant to the addictive process that perpetuates METH and MDMA abuse. Furthermore, our models of selective DA, selective 5-HT, and dual DA/5-HT neurotoxicity by METH, FEN, and MDMA, respectively, are significant in understanding the roles of DA and 5-HT in Pavlovian conditioning. We report that amphetaminesinduced DA and 5-HT neurotoxicity differentially modulate appetitive conditioning by drug reward and aversive conditioning by $\mathrm{LiCl}$, and demonstrate opposing roles of DA and 5-HT in Pavlovian conditioning.

\section{MATERIALS AND METHODS}

\section{Subjects}

Male Swiss Webster mice (8 weeks old; 28-32 g; Charles River, Wilmington, MA) were maintained on a 12-h light/ dark lighting schedule at a room temperature of $22 \pm 0.5^{\circ} \mathrm{C}$ and housed in groups of five with free access to food and water. Animals were habituated for 5 days in the Division of Veterinary Resources (University of Miami School of Medicine) before drug treatments and then housed in groups of two and three following the neurotoxic or saline treatments. Animal care was in accordance with the Guide for the Care and Use of Laboratory Animals (National Research Council, National Academy Press, 1996) and was approved by the University of Miami Animal Care and Use Committee.

\section{Drugs and Chemicals}

$( \pm)$ MDMA-HCl was a gift from the National Institute on Drug Abuse (Bethesda, MD). (d) METH-HCl, ( \pm ) FEN-HCl, Cocaine- $\mathrm{HCl}$, and $\mathrm{LiCl}$ were purchased from Sigma (St Louis, MO). Drug solutions were prepared in saline and $\mathrm{LiCl}$ in distilled water. $\left[{ }^{3} \mathrm{H}\right] \mathrm{Mazindol}(24 \mathrm{Ci} / \mathrm{mmol})$ and $\left[{ }^{3} \mathrm{H}\right] \mathrm{ci}$ talopram $(81 \mathrm{Ci} / \mathrm{mol})$ were purchased from New England Nuclear (Wilmington, Del., USA).

\section{Schedule of Drug Administration}

Mice were pretreated with one of the following neurotoxic regimens: METH $(5 \mathrm{mg} / \mathrm{kg} \times 3,4 \mathrm{~h}$ apart in 1 day $)$, FEN $(25 \mathrm{mg} / \mathrm{kg} \times 2,6 \mathrm{~h}$ apart for 2 days), and MDMA $(15 \mathrm{mg} / \mathrm{kg}$ $\times 2,6 \mathrm{~h}$ apart for 2 days). The amphetamine doses chosen were based on our previous studies on the neurotoxic effects of METH (Itzhak and Ali, 1996; Itzhak et al, 2002); FEN (Itzhak et al, 2003b), and MDMA (Itzhak et al, 2003a) in Swiss Webster mice. Control mice received saline $(0.9 \%$ $\mathrm{NaCl}$ ) injections. Animals' weights were monitored daily prior to drug administration and during behavioral testing. Saline-, METH-, FEN-, and MDMA-pretreated mice were divided into three separate groups to conduct: (1) METH 
CPP, (2) cocaine CPP, and (3) LiCl CPA. Conditioning experiments commenced 3 days following the last exposure to neurotoxic regimen of the amphetamines. For CPP experiments, saline-, METH-, FEN-, and MDMA-pretreated mice were conditioned for 4 alternating days with either METH $(0.125,0.25,0.5$, and $1.0 \mathrm{mg} / \mathrm{kg} ; n=10$ per pretreatment, per dose) or cocaine $(15 \mathrm{mg} / \mathrm{kg} ; n=10$ per pretreatment group). For CPA experiments, saline $(n=16)-, \mathrm{METH}$ $(n=16)$-, FEN $(n=9)$-, and MDMA $(n=9)$-pretreated mice were conditioned with $\mathrm{LiCl}(150 \mathrm{mg} / \mathrm{kg})$. The dosage of $\mathrm{LiCl}$ was chosen based on our previous studies in Swiss Webster mice (Martin and Itzhak, 2000). All treatments were administered intraperitoneally (i.p.) in a volume of 0.1 $\mathrm{ml} / 10 \mathrm{~g}$ body weight.

\section{Behavioral Testing}

CPP and CPA. The CPP design, previously described in detail (Achat-Mendes et al, 2003), commenced 3 days following neurotoxic pretreatments. During habituation (day 1), mice were allowed free exploration of the black and white zones of the CPP apparatus for $20 \mathrm{~min}$. During preconditioning (day 2), the time spent in the black, white, and null zones was recorded for $20 \mathrm{~min}$. Routinely, for appetitive conditioning, the US (METH, cocaine) was paired with the relatively less preferred zone (black and white). For the aversive conditioning, mice were administered $\mathrm{LiCl}$ in the relatively preferred zone (black and white). The conditioning phase (days 3-10) consisted of 8 days of alternating US and saline injections in the particular zones determined during the preconditioning phase. Therefore, each mouse received four US sessions and four saline sessions, $30 \mathrm{~min}$ each (cocaine CPP) or $60 \mathrm{~min}$ each (METH CPP and LiCl CPA). During these sessions, a guillotine door with black and white walls was placed at the center of the CPP cage in order to separate the two zones. On the 11 th day, in the postconditioning phase, mice received a saline injection and were allowed free access to all zones of the apparatus as in the preconditioning phase. Time spent in each zone was recorded for $20 \mathrm{~min}$. Additionally, locomotor activity (LMA) was recorded as the number of beams broken in 20 min during the test sessions for cocaine CPP and $\mathrm{LiCl}$ CPA experiments. The induction of CPP and CPA was evaluated by the difference in time spent in drug-paired zone before and after conditioning. For cocaine CPP and $\mathrm{LiCl} \mathrm{CPA}$ experiments, an additional control group (saline pretreatment and saline conditioning) was included in order to assess the development of CR.

Apparatus. Animals' place preference was monitored by the CPP apparatus, Opto-Max Activity Meter v2.16 (Columbus Instruments, Columbus, $\mathrm{OH}$ ). The CPP cage, $42 \times 20 \times 20 \mathrm{~cm}$, was separated by a removable guillotine door into two zones, one comprising a black floor with four black walls and the other a white floor with four white walls. The apparatus was covered with a transparent Plexiglas lid perforated to allow adequate ventilation. A transparent, colorless, enclosed Plexiglas waiting chamber $(12 \times 8 \times 8 \mathrm{~cm})$ was affixed to one side of the CPP cage at the junction of the black and white compartments. Mice were placed in the waiting chamber and allowed entry via a guillotine door that matched the black/white walls of the
CPP apparatus. The cage was equipped with matching pairs of horizontal sensors mounted alongside opposing lengths (42 cm long). The black and white zones $(21 \times 20 \times 20 \mathrm{~cm})$ were each scanned at a rate of $10 \mathrm{~Hz}$ by seven infrared beams, spaced at $2.54 \mathrm{~cm}$ intervals. A null zone was assigned at the interface of the black and white zones in the center of the box and was monitored by two beams. Information collected from sensors was analyzed and recorded by the Opto-Max interface.

\section{Determination of Dopamine and Serotonin Nerve Terminal Markers}

All animals were killed 3 days following the termination of the behavioral testing. Striatum (caudate putamen only), frontal cortex, hippocampus (dorsal and ventral), and amygdala were obtained by gross dissection and immediately frozen on dry ice. Routinely, tissue from one hemisphere was used for high-performance liquid chromatography (HPLC) combined with electrochemical detection for the determination of concentrations of DA, 3, 4-dihydroxyphenylacetic acid (DOPAC), homovanillic acid (HVA), 5-HT, and 5hydroxyindole acetic acid (5-HIAA) (Itzhak et al, 1998). Tissue from the other hemisphere was used to determine the density of DA transporter (DAT) and 5-HT transporter (5-HTT) binding sites by saturation binding assays using $\left[{ }^{3} \mathrm{H}\right]$ mazindol $(1-20 \mathrm{nM})$ and $\left[{ }^{3} \mathrm{H}\right]$ citalopram $(0.5-5 \mathrm{nM})$ as described previously (Itzhak et al, 1998, 2003a).

\section{Data Analysis}

Behavioral test results are presented as the mean \pm SEM difference between the times spent in the drug-paired compartment before and after conditioning. Comparisons between saline and drug conditioning were analyzed by Student's $t$-test. Results of METH CPP were analyzed by a two-way analysis of variance (ANOVA) for effect of pretreatment $\times$ dose. Results of cocaine CPP and LiCl CPA were analyzed by one-way ANOVA. Significant main effects were followed by post hoc comparisons using Bonferroni and Newman-Keuls test to evaluate the magnitude of preference/aversion as a function of pretreatment. Differences in DA and 5-HT markers as a function of pretreatments were analyzed by one-way ANOVA followed by post hoc Newman-Keuls test. A significance criterion of $p<0.05$ was used for all analyses.

\section{RESULTS}

\section{Effect of METH, FEN, and MDMA Neurotoxicity on METH-Induced CPP}

Effect of METH neurotoxicity. During the preconditioning phase (pre-CPP), the time spent in the black, white, and null zones was recorded. Of the saline-pretreated animals $(n=80), 48 \%$ spent more time in the black zone $(n=38)$, $45 \%$ preferred the white zone $(n=36)$, and $7 \%$ had no preference. Of the METH neurotoxic animals $(n=80), 44 \%$ spent more time in the black zone $(n=35)$ and $41 \%$ preferred the white zone $(n=33)$, and $15 \%$ had no preference. Time spent in the 'preferred' zone was an average of $112 \pm 15 \mathrm{~s}$ (out of $1200 \mathrm{~s}$ ) more than in the 
alternate zone for both groups. Results revealed that there were no significant differences in initial preference due to METH neurotoxicity. Routinely, animals were assigned to receive METH conditioning in the less preferred zone. Time spent in the drug-paired zones during pre-CPP for salinepretreated mice $(440 \pm 19)$ and METH neurotoxic mice $(410 \pm 32)$ was not significantly different (unpaired $t$-test: $t=0.8061 ; \mathrm{df}=158 ; p=0.4214)$, indicating that there was no bias in assignment of drug-paired zone between groups.

CPP was conducted with various doses of METH $(0.125$, $0.25,0.5$. and $1.0 \mathrm{mg} / \mathrm{kg}$ ) to achieve a dose response effect. Figure 1a illustrates that the increase in time spent in the drug-paired zone was markedly reduced for the METH neurotoxic mice compared to controls after conditioning with METH $0.25 \mathrm{mg} / \mathrm{kg}$ (METH $108 \pm 38$; saline $249 \pm 18 \mathrm{~s}$ ) and $0.5 \mathrm{mg} / \mathrm{kg}$ (METH $159 \pm 16$; saline $333 \pm 15 \mathrm{~s}$ ). Two-way ANOVA for comparison of the magnitude of CPP induction revealed a significant dose effect $(\mathrm{F}[3,72]=22.50$; $p<0.0001)$ and a significant pretreatment effect $(\mathrm{F}[1,72]=$ $19.50 ; p<0.0001)$. Post hoc Bonferroni tests revealed a significant difference between METH- and saline pretreatment when conditioned with $0.25(p<0.01)$ and $0.5 \mathrm{mg} / \mathrm{kg}$ $(p<0.001)$ (Figure 1a). The results indicate that METH neurotoxicity significantly impaired place preference at the optimal METH conditioning doses. The magnitude of CPP in the saline and METH neurotoxic groups after conditioning by $0.125 \mathrm{mg} / \mathrm{kg}$ METH was $39 \pm 46$ and $32 \pm 21 \mathrm{~s}$, respectively. The magnitude of $\mathrm{CPP}$ in the saline and METH groups following conditioning by $1.0 \mathrm{mg} / \mathrm{kg} \mathrm{METH}$ was $113 \pm 34$ and $82 \pm 24$, respectively. Post hoc Bonferroni tests revealed that the magnitude of CPP induced by 0.125 and $1.0 \mathrm{mg} / \mathrm{kg}$ METH was significantly lower than that induced by the intermediate doses 0.25 and $0.5 \mathrm{mg} / \mathrm{kg}$ for both saline $(p<0.01)$ and METH neurotoxic $(p<0.05)$ groups. This type of bell-shape dose-response of METH CPP was also observed by others (Cunningham and Noble, 1992) and may be due to diminution in the rewarding effect of high dose of METH.

Effect of FEN neurotoxicity. Time spent in the black, white, and null zones was recorded for saline and FEN neurotoxic animals during pre-CPP. Of the saline-pretreated animals $(n=60), 50 \%$ spent more time in the black zone $(n=30)$, $28 \%$ preferred the white zone $(n=17)$, and $22 \%$ had no preference. Of the FEN neurotoxic animals $(n=60), 52 \%$ spent more time in the black zone $(n=31), 32 \%$ preferred the white zone $(n=19)$, and $16 \%$ had no preference. Time spent in the 'preferred' zone was an average of $102 \pm 21 \mathrm{~s}$ (out of $1200 \mathrm{~s}$ ) more than in the alternate zone for both groups. Results showed that there were no significant differences in initial zone preference due to FEN neurotoxicity. Time spent in the drug-paired zones during pre-CPP for saline-pretreated mice $(462 \pm 41)$ and FEN neurotoxic mice $(412 \pm 34)$ was not significantly different (unpaired $t$-test: $t=0.9387 ; \mathrm{df}=118 ; p=0.3498$ ), indicating that there was no bias between groups in assignment of drug-paired zone.

Figure $1 \mathrm{~b}$ shows that the magnitude of CPP was noticeably enhanced following FEN neurotoxic treatment compared to controls, after conditioning by METH $0.25 \mathrm{mg} / \mathrm{kg}$ (FEN $448 \pm 40$; saline $256 \pm 28 \mathrm{~s}$ ) and $0.5 \mathrm{mg} / \mathrm{kg}$
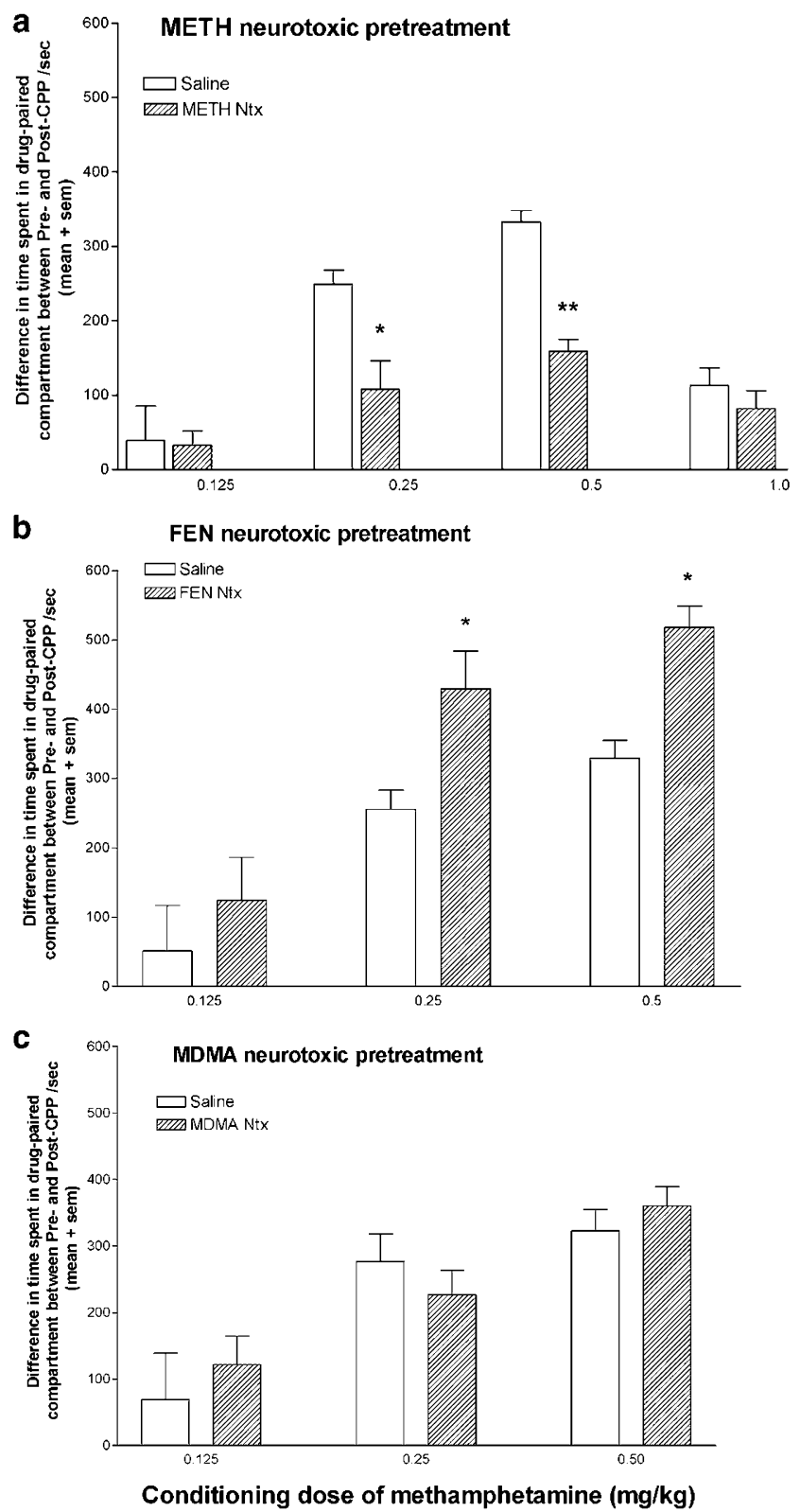

Figure I Effect of METH, FEN, and MDMA neurotoxicity on METHinduced CPP. At 3 days following exposure of mice to saline or neurotoxic regimen of amphetamines ( $n=10$ per pretreatment group), METH $(0.125,0.25,0.5$, and $1.0 \mathrm{mg} / \mathrm{kg} ; n=10$ per conditioning dose) CPP was investigated. Results are presented as the difference in mean \pm SEM time (seconds) spent in the drug-paired zone (time spent after conditioning-time spent before conditioning). (a) METH-pretreated mice showed that the magnitude of CPP was significantly reduced compared to that of controls when conditioned with $0.25 \mathrm{mg} / \mathrm{kg}(* p<0.0 \mathrm{I})$ and $0.5 \mathrm{mg} / \mathrm{kg}$ (*** $<0.00 \mathrm{I}$ ) METH. The magnitude of CPP attained at 0.125 and $1.0 \mathrm{mg} /$ $\mathrm{kg}$ METH was not significantly different compared to controls. (b) FENpretreated mice showed significantly enhanced CPP magnitude compared to controls when conditioned with 0.25 and $0.5 \mathrm{mg} / \mathrm{kg}(* p<0.05) \mathrm{METH}$. CPP at the $0.125 \mathrm{mg} / \mathrm{kg}$ dose was not different from control. (c) MDMApretreated mice exhibited no significant difference in CPP magnitude compared to controls at any of the doses tested.

(FEN 518 \pm 31 ; saline $330 \pm 26 \mathrm{~s}$ ). Two-way ANOVA for comparison of the magnitude of CPP induction resulted in a significant dose effect $(\mathrm{F}[2,54]=26.91 ; p<0.0001)$ and a significant pretreatment effect $(\mathrm{F}[1,54]=14.72 ; p=0.0003)$. 
Post hoc Bonferroni tests confirmed a significant difference between FEN- and saline pretreatment when conditioned by 0.25 and $0.5 \mathrm{mg} / \mathrm{kg} \mathrm{METH}(p<0.05)$ (Figure $1 \mathrm{~b})$. The results indicate that FEN neurotoxicity significantly enhanced place preference at the optimum conditioning doses of METH. The magnitude of CPP that developed at $0.125 \mathrm{mg} / \mathrm{kg} \mathrm{METH}$ (saline $51 \pm 66 \mathrm{~s}$; FEN $125 \pm 73$ ) was significantly lower than that developed by higher doses $(p<0.05$; Figure 1b).

Effect of MDMA neurotoxicity. Time spent in the black, white, and null zones was recorded for saline and MDMA neurotoxic animals during pre-CPP. Of the saline-pretreated animals $(n=60), 55 \%$ spent more time in the black zone $(n=33), 40 \%$ preferred the white zone $(n=24)$, and $5 \%$ had no preference. Of the MDMA neurotoxic animals $(n=60), 47 \%$ spent more time in the black zone $(n=28)$, $43 \%$ preferred the white zone $(n=26)$, and $10 \%$ had no preference. Time spent in the 'preferred' zone was an average of $121 \pm 18 \mathrm{~s}$ (out of $1200 \mathrm{~s}$ ) more than in the alternate zone for both groups. Results showed that there were no significant differences in initial zone preference due to MDMA neurotoxicity. Time spent in the drug-paired zones during pre-CPP for saline-pretreated mice $(489 \pm 33)$ and MDMA neurotoxic mice $(529 \pm 59)$ was not significantly different (unpaired $t$-test: $t=0.5917$; $\mathrm{df}=118 ; p=0.5552$ ), indicating that there was no bias between groups in assignment of drug-paired zone.

Figure 1c depicts the effect of MDMA-induced neurotoxicity on place preference. The magnitude of CPP in the MDMA and saline groups after conditioning by METH was similar: $0.125 \mathrm{mg} / \mathrm{kg}$ (MDMA $70 \pm 18 ;$ saline $64 \pm 42 \mathrm{~s}$ ), $0.25 \mathrm{mg} / \mathrm{kg}$ (MDMA 274 \pm 38 ; saline $231 \pm 41 \mathrm{~s}$ ), and $0.5 \mathrm{mg} / \mathrm{kg}$ (MDMA $360 \pm 29$; saline $323 \pm 32 \mathrm{~s}$ ). Two-way ANOVA resulted in a significant dose effect $(\mathrm{F}[2,54]=$ 32.79; $p<0.0001)$, but insignificant pretreatment effect $(\mathrm{F}[1,54]=1.029 ; p=0.3148)$. The results indicate that MDMA neurotoxicity had no apparent effect on METH CPP.

\section{Effect of METH, FEN, and MDMA Neurotoxicity on Cocaine-Induced CPP}

To further investigate the consequences of DA and 5-HT neurotoxicity on appetitive conditioning by drug reward, cocaine CPP was conducted. Conditioning by cocaine $(15 \mathrm{mg} / \mathrm{kg})$ resulted in significant CPP in saline-pretreated mice (Figure 2; saline/saline vs saline/cocaine; $p=0.0041$, two-tailed unpaired Student's $t$-test). One-way ANOVA for comparison of the magnitude of cocaine CPP between the saline and the three neurotoxic groups resulted in a significant pretreatment effect $(\mathrm{F}[3,36]=12.34 ; p<0.0001)$. Post hoc Bonferroni test indicated that mice pretreated with METH exhibited significantly less CPP than controls: $75 \pm 18 \mathrm{~s}(\mathrm{METH})$ compared to $206 \pm 26 \mathrm{~s}$ (saline); $p<0.05$. However, mice pretreated with FEN displayed significantly higher CPP compared to saline: $351 \pm 50 \mathrm{~s}$ (FEN) vs $206 \pm 26$ s (saline); $p<0.01$. Similar to the results of METH CPP, MDMA pretreatment had no significant effect on the magnitude of cocaine CPP compared to saline: $188 \pm 25 \mathrm{~s}$ (MDMA) vs 206 $\pm 26 \mathrm{~s}$ (saline); $p>0.05$.

The effect of neurotoxicity on spontaneous LMA in a drug-free state was recorded during the CPP test sessions. The numbers of beams broken during the 20 min session in

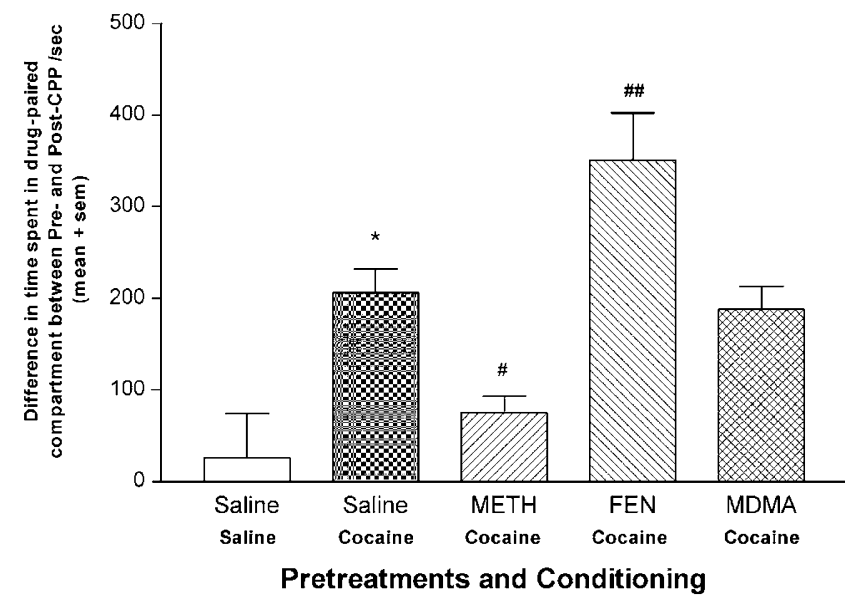

Figure 2 Effect of METH, FEN, and MDMA neurotoxicity on cocaineinduced CPP. At 3 days following exposure of mice to saline or neurotoxic regimen of amphetamines $(n=10$ per pretreatment group), cocaine (15 mg/kg) CPP was investigated. Additional control group $(n=10)$ received saline instead of cocaine. Results are presented as the difference in mean \pm SEM time (seconds) spent in the drug-paired zone (time spent after conditioning-time spent before conditioning). The saline/cocaine group exhibited significant CPP compared to saline/saline group $(* p<0.01)$. The magnitude of CPP in the METH/cocaine group was significantly lower than in saline/cocaine group ( $\left.{ }^{\#} p<0.05\right)$. The magnitude of CPP in the FEN/cocaine group was significantly higher than in the saline/ cocaine group $\left({ }^{\# \#} p<0.01\right)$. No significant difference between MDMA/ cocaine and saline/cocaine groups was observed.

the four groups were as follows: saline $(1564 \pm 82), \mathrm{METH}$ $(1815 \pm 111)$, FEN $(1580 \pm 56)$, and MDMA $(1811 \pm 88)$. Oneway ANOVA resulted in insignificant pretreatment effect $(\mathrm{F}[3,36]=2.594 ; p=0.0676)$. The lack of significant effect of neurotoxicity upon spontaneous LMA suggests that motor performance did not influence the expression of place preference.

\section{Effect of METH, FEN, and MDMA Neurotoxicity on LiCl-Induced CPA}

In order to investigate the consequences of DA and 5-HT neurotoxicity on aversive conditioning, $\mathrm{LiCl} \mathrm{CPA}$ was performed. Conditioning by $\mathrm{LiCl}(150 \mathrm{mg} / \mathrm{kg})$ resulted in significant CPA in saline-pretreated mice (Figure 3; saline/ saline $v s$ saline/LiCl; $p=0.0008$, two-tailed unpaired Student's $t$-test). One-way ANOVA for comparison of the magnitude of CPA between the saline and neurotoxic groups resulted in a significant pretreatment effect $(\mathrm{F}[3,46]=2.999 ; p<0.05)$. Post hoc Newman-Keuls test indicated that mice pretreated with METH and FEN exhibited CPA similar to controls: $-159 \pm 19 \mathrm{~s}$ (METH), $-146 \pm 43$ s (FEN), $-159 \pm 24$ s (saline); $p>0.05$. However, mice pretreated with MDMA displayed significantly reduced CPA compared to saline: $-43 \pm 42$ s (MDMA); $p<0.05$.

LMA was monitored during CPA test sessions and was found to be similar for all groups: saline $(1732 \pm 104)$, METH $(1725 \pm 136)$, FEN $(1491 \pm 90)$, and MDMA $(1704 \pm 114)$. One-way ANOVA resulted in insignificant pretreatment effect $(\mathrm{F}[3,46]=0.7211 ; p=0.5446)$. Thus, the expression of place aversion was not influenced by potential alteration in spontaneous LMA due to neurotoxicity. 


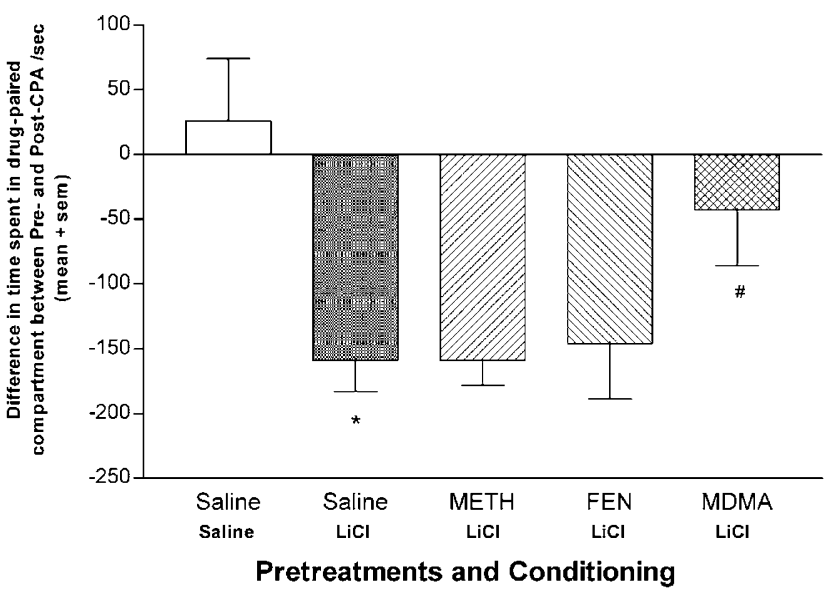

Figure 3 Effect of METH, FEN, and MDMA neurotoxicity on $\mathrm{LiCl}$ induced CPA. At 3 days following exposure of mice to saline $(n=16)$ or neurotoxic regimen of amphetamines (METH, $n=16$; FEN, $n=9$; MDMA, $n=9), \mathrm{LiCl}(150 \mathrm{mg} / \mathrm{kg})$ CPA was investigated. Additional control group $(n=10)$ received saline instead of $\mathrm{LiCl}$. Results are presented as the difference in mean \pm SEM time (seconds) spent in the drug-paired zone (time spent after conditioning-time spent before conditioning). The saline/ $\mathrm{LiCl}$ group exhibited significant CPA compared to saline/saline group $(* P<0.01$ ). The magnitude of CPA in the METH/LiCl and FEN/LiCl groups was not significantly different than saline/LiCl group. The magnitude of CPA in the MDMA/LiCl group was significantly lower than in the saline/LiCl group $\left({ }^{\#} p<0.0 \mathrm{I}\right)$.

\section{Post-Mortem Analysis of DA and 5-HT Markers in Brain}

In order to determine the magnitude of dopaminergic and serotinergic neurotoxicity as a result of pretreatment with neurotoxic regimens of amphetamines, the levels of DA, DAT, 5-HT, and 5-HTT were determined in the striatum, frontal cortex (FC), hippocampus, and amygdala 3 days following completion of behavioral testing. Individual binding experiments revealed that conditioning by METH $(0.25 \mathrm{mg} / \mathrm{kg})$, cocaine $(15 \mathrm{mg} / \mathrm{kg})$, and $\mathrm{LiCl}(150 \mathrm{mg} / \mathrm{kg})$ had no significant effect on the levels of DA, 5-HT, and their corresponding transporters. Therefore, the results for each neurotoxic treatment group conditioned by METH, cocaine, or $\mathrm{LiCl}$ were combined and are presented in Table 1. METH induced selective depletion of DA nerve terminal markers (DA and DAT) in striatum ( -44 and $-55 \%), \mathrm{FC}(-61$ and $-34 \%)$, and amygdala ( -42 and $-46 \%)$ compared to salinetreated controls; $p<0.05$. FEN administration selectively reduced 5-HT nerve terminal markers (5-HT and 5-HTT) in striatum ( -65 and $-62 \%)$, FC ( -73 and $-72 \%)$, hippocampus ( -52 and $-62 \%)$, and amygdala $(-82$ and $-73 \%)$; $p<0.05$. MDMA neurotoxicity resulted in depletion of both DA and 5-HT nerve terminal markers. DA and DAT were significantly reduced in the striatum $(-34$ and $-45 \%)$, FC $(-56$ and $-28 \%)$, and amygdala $(-31$ and $-30 \%)$. 5-HT and 5-HTT were also significantly depleted in the striatum $(-40$ and $-29 \%)$, FC ( -35 and $-41 \%)$, hippocampus $(-31$ and $-28 \%)$, and amygdala $(-75$ and $-37 \%) ; p<0.05$.

\section{DISCUSSION}

The aim of the present study was to investigate the influence of amphetamines-induced neurotoxicity on appetitive and aversive Pavlovian learning. We have demonstrated that administration of neurotoxic regimens of amphetamine to Swiss Webster mice significantly diminished monoamine markers in the amygdala, hippocampus, frontal cortex, and striatum in a selective manner. The extent of depletion of DA and 5-HT axon terminal markers depends on several variables including the specific amphetamine analog, dosage of drug administration, animal species (Stone et al, 1987), and the strain of rodents (Kita et al, 2003). In rats, METH causes both DA and 5-HT neurotoxicity (Brown and Molliver, 2000; Peat et al, 1983) and MDMA causes primarily 5-HT neurotoxicity (Gibb et al, 1990). In mice, METH causes selective DA neurotoxicity (eg Itzhak and Achat-Mendes, 2004; Table 1). While previous studies found that MDMA is neurotoxic to DA but not 5-HT containing neurons in C57/BL mice (Miller and O'Callaghan, 1994), we found that MDMA causes depletion of both DA and 5-HT markers in Swiss Webster mice (Itzhak et al, 2003a; Table 1). Thus, the Swiss Webster mouse model allowed us to develop selective neuronal depletion of DA (METH) and 5-HT (FEN) markers as well as dual DA/5-HT (MDMA) depletion. Selective deficits in these monoamine systems appear to influence appetitive and aversive Pavlovian learning. The major findings of the present study are: (1) selective dopaminergic and serotonergic neurotoxicity caused by amphetamines have opposing influences on appetitive conditioning by drug reward, (2) simultaneous injury to both DA and 5-HT systems by amphetamines-induced neurotoxicity impairs aversive conditioning by $\mathrm{LiCl}$, and (3) amphetamines-induced DA and 5-HT neurotoxicity in mice modulate appetitive Pavlovian conditioning, comparable to lesions of DA and 5-HT systems by known neurotoxins.

In a previous study we reported that METH neurotoxicity significantly reduced the magnitude of METH $(0.5 \mathrm{mg} / \mathrm{kg})$ CPP (Itzhak et al, 2002). It is possible that pre-exposure to a neurotoxic dose of METH could attenuate METH CPP as a result of either tolerance or sensitization to METH. For instance, we demonstrated that a neurotoxic regimen of METH (Itzhak et al, 2002) and MDMA (Itzhak et al, 2003a) sensitized the locomotor response to diverse psychostimulants. In order to determine whether the reduced METH CPP was due to tolerance or sensitization, a dose response for METH CPP was investigated in this study. Results suggest that METH neurotoxicity produced neither tolerance nor sensitization to the rewarding effect of METH. Had tolerance developed, the magnitude of CPP induced by $1 \mathrm{mg} / \mathrm{kg}$ METH should have been higher than that caused by $0.5 \mathrm{mg} / \mathrm{kg}$ METH in the METH neurotoxic group. Had sensitization developed, the lower dose of METH (0.25 $\mathrm{mg} / \mathrm{kg}$ ) should have produced higher CPP in the METH neurotoxic group compared to controls. Rather, results show that the magnitude of CPP at the optimal doses was reliably lower in the METH neurotoxic group compared to control (Figure 1a).

It is also possible that METH-induced neurotoxicity specifically disrupted subsequent METH conditioning, thereby diminishing CPP. Thus, cocaine CPP experiments were performed to investigate Pavlovian conditioning induced by a psychostimulant other than the applied neurotoxic amphetamine. Results of cocaine CPP were similar to METH CPP (Figure 2), indicating that METH- 
Table I Levels of DA, DAT, 5-HT, and 5-HTT in the Mouse Striatum, Frontal Cortex, Hippocampus, and Amygdala Following Administration of Neurotoxic Amphetamine

\begin{tabular}{|c|c|c|c|c|}
\hline & Saline & METH ntx & FEN $n$ tx & MDMA ntx \\
\hline \multicolumn{5}{|l|}{ Striatum } \\
\hline DA & $618 \pm 25$ & $348 \pm 14(-44 \%)^{*}$ & $563 \pm 31(-7 \%)$ & $409 \pm 31(-34 \%)^{*}$ \\
\hline DAT & $1608 \pm 84$ & $723 \pm 42(-55 \%)^{*}$ & $|59| \pm 102(-1 \%)$ & $884 \pm 64(-45 \%)^{*}$ \\
\hline $5-\mathrm{HT}$ & $51 \pm 3$ & $48 \pm 4(-6 \%)$ & $18 \pm \mid(-65 \%)^{*}$ & $31 \pm 2(-40 \%)^{*}$ \\
\hline $5-\mathrm{HTT}$ & $425 \pm 21$ & $459 \pm 32(+9 \%)$ & $|6| \pm||(-62 \%) *$ & $302 \pm 14(-29 \%) *$ \\
\hline DA & $49 \pm 3$ & $19 \pm 2(-61 \%)^{*}$ & $47 \pm 3(-4 \%)$ & $22 \pm 2(-56 \%)^{*}$ \\
\hline DAT & $182 \pm 6$ & $120 \pm 5(-34 \%)^{*}$ & $179 \pm 6(-2 \%)$ & $|3| \pm 5(-28 \%)^{*}$ \\
\hline $5-\mathrm{HT}$ & $26 \pm 1$ & $27 \pm 2(+4 \%)$ & $7 \pm 1(-73 \%)^{*}$ & $17 \pm \mid(-35 \%)^{*}$ \\
\hline $5-\mathrm{HTT}$ & $387 \pm 28$ & $406 \pm 37(+5 \%)$ & $108 \pm 12(-72 \%)^{*}$ & $23 \mid \pm 11(-41 \%)^{*}$ \\
\hline $5-\mathrm{HT}$ & $31 \pm 2$ & $29 \pm 2(-7 \%)$ & $15 \pm \mid(-52 \%)^{*}$ & $22 \pm 2(-31 \%)^{*}$ \\
\hline $5-\mathrm{HTT}$ & $421 \pm 25$ & $433 \pm 29(+3 \%)$ & $159 \pm 12(-62 \%) *$ & $305 \pm 11(-28 \%)^{*}$ \\
\hline \multicolumn{5}{|l|}{ Amygdala } \\
\hline DA & $36 \pm 3$ & $21 \pm 2(-42 \%)^{*}$ & $38 \pm 3(+5 \%)$ & $25 \pm 2(-31 \%)^{*}$ \\
\hline DAT & $244 \pm 20$ & $132 \pm 19(-46 \%) *$ & $228 \pm 15(-7 \%)$ & $172 \pm 12(-30 \%)^{*}$ \\
\hline $5-\mathrm{HT}$ & $28 \pm 1$ & $32 \pm 2(+14 \%)$ & $5 \pm 2(-82 \%) *$ & $7 \pm 1(-75 \%)^{*}$ \\
\hline $5-\mathrm{HTT}$ & $810 \pm 21$ & $757 \pm 32(-7 \%)$ & $224 \pm 9(-73 \%)^{*}$ & $511 \pm 17(-37 \%)^{*}$ \\
\hline
\end{tabular}

Levels of dopaminergic and serotonergic markers in specific brain regions were determined following completion of behavioral testing, that is, 2 weeks following administration of METH $(5 \mathrm{mg} / \mathrm{kg} \times 3)$, FEN $(25 \mathrm{mg} / \mathrm{kg} \times 4)$, and MDMA $(15 \mathrm{mg} / \mathrm{kg} \times 4)$. DA and 5 -HT concentrations are expressed in $\mathrm{ng} / \mathrm{l} 00 \mathrm{mg}$ tissue and DAT and 5 -HTT densities in fmole/mg protein. Significant reductions were confirmed by one-way ANOVA, followed by Newman-Keuls comparison $(* p<0.05)$.

$\mathrm{ND}=$ not detectable.

induced dopaminergic neurotoxicity impairs appetitive conditioning by drug reward. Since the process of Pavlovian learning is dependent on (a) the affective state produced by the US and (b) consolidation of the association between the US and CS, these results suggest that METHinduced DA neurotoxicity can impair either the affective state produced by drug reward and/or the associative learning process.

To further investigate the hypothesis that METH-induced neurotoxicity can impair associative learning, $\mathrm{LiCl} \mathrm{CPA}$ was explored. Unlike appetitive conditioning by drug reinforcement, the aversive response of $\mathrm{LiCl}$ conditioning is independent of mesolimbic DA release (Bassareo et al, 1996); therefore, CPA experiments directly test the influence of amphetamines-induced neurotoxicity on associative learning. However, results revealed that LiCl-induced CPA was not affected by METH neurotoxicity, suggesting that dopaminergic deficiency alone does not alter aversive conditioning (Figure 3). The diminished CPP observed following METH-induced DA neurotoxicity is consistent with lesion experiments, showing that 6-hydroxydopamine (6-OHDA) lesions of DA cell bodies in the ventral tegmental area (Roberts and Koob, 1982) and DA terminals in the nucleus accumbens shell (Pettit et al, 1984; Sellings and Clarke, 2003) reduced the rewarding effect of cocaine and amphetamine. It is therefore likely that the reduced CPP response following METH-induced DA neurotoxicity was primarily due to a diminished DA-mediated affective state.

In contrast, 5-HT neurotoxicity induced by FEN significantly increased both METH and cocaine place preference (Figures $1 \mathrm{~b}$ and 2), implying a role for $5-\mathrm{HT}$ in the affective state produced by the US and/or associative learning of the US-CS. However, the findings that 5-HT neurotoxicity did not affect CPA (Figure 3 ) suggest that the influence on CPP was primarily due to modulation of the affective state produced by drug reward. Fletcher et al (1999) reported that injection of the neurotoxin 5,7dihydroxytryptamine (5,7-DHT) into the dorsal and medial Raphe nuclei reduced striatal and hippocampal 5-HT levels (similar to FEN neurotoxicity; Table 1), and increased amphetamine-induced reward. This finding supports the hypothesis that 5-HT systems can inhibit drug reward (Bardo, 1998), and suggests that 5-HT depletion removes the inhibitory control of 5-HT on mesolimbic DA neurons, thereby enhancing METH and cocaine CPP. Studies in rats reported an increase in METH place preference after METH-induced neurotoxicity (Gehrke et al, 2003). This outcome may be due to the 5-HT neurotoxicity elicited by METH in rats (Gehrke et al, 2003), whereas METH induces only DA neurotoxicity in mice (Table 1). 
Interestingly, the finding that the magnitudes of CPP in MDMA and saline-pretreated mice were similar (Figures 1c and 2) suggests that a deficit in both DA and 5-HT systems by MDMA has no apparent effect on appetitive Pavlovian conditioning. If DA mediates the rewarding effect of the drug and 5-HT exerts an inhibitory action on DA neurons, then injury to both systems would diminish both the rewarding and inhibitory roles of the DA and 5-HT systems, respectively, hence the rationale that there would be no net effect on CPP. It is therefore possible that the opposing effects of DA and 5-HT on appetitive conditioning may mask any individual effect of monoaminergic insult in this paradigm. However, the significantly reduced $\mathrm{LiCl} \mathrm{CPA}$ response following MDMA neurotoxic exposure (Figure 3) suggests that both DA and 5-HT systems are necessary for optimal associative learning. By this reasoning, it may be expected that associative learning in METH and cocaine CPP will be also attenuated following MDMA-induced neurotoxicity. However, associative learning by druginduced appetitive conditioning may be facilitated, compared to associative learning by aversive conditioning (LiCl). Since low doses of psychostimulants, such as amphetamine, have memory-enhancing properties (Packard and Teather, 1998), it is possible that conditioning by low doses of METH and cocaine, but not $\mathrm{LiCl}$, facilitated the acquisition/expression of place conditioning in the MDMA neurotoxic group.

Amphetamines-induced neurotoxicity was maintained throughout conditioning as revealed by the deficits in monoamine concentrations and transporter densities, observed after behavioral experiments. Results illustrate selective reduction of DA markers by METH neurotoxicity; 5-HT markers by FEN neurotoxicity; and both DA and 5-HT markers by MDMA neurotoxicity in the striatum, frontal cortex, hippocampus, and amygdala (Table 1). The global reduction of monoamine markers observed in our mouse models of amphetamines-induced neurotoxicity is consistent with other reports (Thompson et al, 2004; McCann et al, 1998), indicating that brain regions innervated by DA and/ or 5-HT (striatum, frontal cortex, hippocampus, and amygdala) are all potential targets for amphetaminesinduced neurotoxicity. Investigation of the neural substrates involved in Pavlovian conditioning has centered primarily on amygdala nuclei, which process distinct sensory stimuli involved in emotional learning (Swanson and Petrovich, 1998) and the hippocampus, which processes contextual stimuli and has a role in spatial learning (Phillips and LeDoux, 1992). However, DA and 5-HT ascending projections to the striatum (Olmstead and Franklin, 1996), nucleus accumbens (Di Chiara, 2002), and prefrontal cortex (Isaac et al, 1989) have also been implicated in Pavlovian conditioning. Thus, due to the roles of DA and 5-HT in cognition and reward, the very neural substrates that are recruited in Pavlovian conditioning are also potential targets for amphetamines-induced neurotoxicity. It is therefore likely that the deficits in DA and 5-HT markers we observed in the various brain regions modulated Pavlovian conditioning.

Altogether, experiments suggest that amphetaminesinduced neurotoxicity can alter appetitive Pavlovian conditioning primarily through modulation of the affective state produced by drug reinforcement. METH-induced DA neurotoxicity can impair the affective state produced by drug reinforcement, resulting in low CPP. FEN-induced 5-HT neurotoxicity can augment this affective state, resulting in enhanced CPP. However, selective damage to either the 5-HT system or the DA system is not sufficient to impair aversive conditioning. MDMA-induced dual DA and 5-HT neurotoxicity has no apparent influence on the affective state produced by drug reinforcement; however, combined damage to both DA and 5-HT systems, by MDMA neurotoxicity, can disrupt performance in tasks that require aversive associative learning.

The finding that Pavlovian conditioning by drug reinforcement can be modulated by amphetamines-induced neurotoxicity may have major implications in drug addiction. Impairment of the affective state of subsequent drug abuse after METH neurotoxicity suggests the possibility of a practice whereby METH administration is perpetuated by pursuit of the original rewarding effect of the drug. Enhancement of the affective state by 5 -HT neurotoxicity has implications for MDMA-induced depletion of 5-HT nerve terminal markers in humans. If 5-HT neurotoxicity enhances the incentive value of psychostimulants, it is likely that drug-seeking behavior in MDMA abusers will be amplified. Notably, results of the CPP experiments demonstrate that amphetamines-induced DA and 5-HT neurotoxicity modulates Pavlovian conditioning in a manner similar to 6-OHDA and 5,7-DHT lesions of ascending DA and 5-HT neurons, respectively, indicating that amphetamines of abuse may exert similar behavioral effects as well-known neurotoxins.

\section{ACKNOWLEDGEMENTS}

This work was supported by RO1DA12867 from the National Institute on Drug Abuse, National Institute of Health. We thank Karen Anderson for technical assistance in this project. Cindy Achat-Mendes is a Lois Pope LIFE fellow.

\section{REFERENCES}

Achat-Mendes C, Anderson KL, Itzhak Y (2003). Methylphenidate and MDMA adolescent exposure in mice: long-lasting consequences on cocaine-induced reward and psychomotor stimulation in adulthood. Neuropharmacology 45: 106-115.

Bardo MT (1998). Neuropharmacological mechanisms of drug reward: beyond dopamine in the nucleus accumbens. Crit Rev Neurobiol 12: 37-67.

Bassareo V, Tanda G, Petromilli P, Giua C, Di Chiara G (1996). Non-psychostimulant drugs of abuse and anxiogenic drugs activate with differential selectivity dopamine transmission in the nucleus accumbens and in the medial prefrontal cortex of the rat. Psychopharmacology (Berl) 124: 293-299.

Bhattachary S, Powell JH (2001). Recreational use of 3,4methylenedioxymethamphetamine (MDMA) or ecstasy: evidence for cognitive impairment. Psychol Med 31: 647-658.

Bolla KI, McCann UD, Ricaurte GA (1998). Memory impairment in abstinent MDMA ('Ecstasy') users. Neurology 51: 1532-1537.

Brown P, Molliver ME (2000). Dual serotonin (5-HT) projections to the nucleus accumbens core and shell: relation of the 5-HT transporter to amphetamine-induced neurotoxicity. J Neurosci 20: $1952-1963$. 
Chang L, Ernst T, Speck O, Patel H, DeSilva M, Leonido-Yee M et al (2002). Perfusion MRI and computerized cognitive test abnormalities in abstinent methamphetamine users. Psychiatry Res 114: 65-79.

Chapman DE, Hanson GR, Kesner RP, Keefe KA (2001). Longterm changes in basal ganglia function after a neurotoxic regimen of methamphetamine. J Pharmacol Exper Ther 296: 520-527.

Cunningham CL, Noble D (1992). Methamphetamine-induced conditioned place preference or aversion depending on dose and presence of drug. Ann NY Acad Sci 654: 431-433.

Davidson C, Gow AJ, Lee TH, Ellinwood EH (2001). Methamphetamine neurotoxicity: necrotic and apoptotic mechanisms and relevance to human abuse and treatment. Brain Res Brain Res Rev 36: 1-22.

Di Chiara G (2002). Nucleus accumbens shell and core dopamine: differential role in behavior and addiction. Behav Brain Res 137: 75-114.

Fletcher PJ, Korth KM, Chambers JW (1999). Selective destruction of brain serotonin neurons by 5,7-dihydroxytryptamine increases responding for a conditioned reward. Psychopharmaco$\log y$ (Berl) 147: 291-299.

Freese T, Miotto K, Reback C (2002). The effects and consequences of selected club drugs. J Subst Abuse Treat 23: 151-156.

Friedman SD, Castaneda E, Hodge GK (1998). Long-term monoamine depletion, differential recovery, and subtle behavioral impairment following methamphetamine-induced neurotoxicity. Pharmacol Biochem Behav 61: 35-44.

Gallagher M, Graham PW, Holland PC (1990). The amygdala central nucleus and appetitive Pavlovian conditioning: lesions impair one class of conditioned behavior. J Neurosci 10: 19061911.

Gehrke BJ, Harrod SB, Cass WA, Bardo MT (2003). The effect of neurotoxic doses of methamphetamine on methamphetamineconditioned place preference in rats. Psychopharmacology (Berl) 166: 249-257.

Gibb JW, Johnson M, Stone D, Hanson GR (1990). MDMA: historical perspectives. Ann N Y Acad Sci 600: 601-612.

Gibson DR, Leamon MH, Flynn N (2002). Epidemiology and public health consequences of methamphetamine use in California's Central Valley. J Psychoactive Drugs 34: 313-319.

Gouzoulis-Mayfrank E, Thimm B, Rezk M, Hensen G, Daumann J (2003). Memory impairment suggests hippocampal dysfunction in abstinent ecstasy users. Prog Neuropsychopharmacol Biol Psychiatry 27: 819-827.

Isaac WL, Nonneman AJ, Neisewander J, Landers T, Bardo MT (1989). Prefrontal cortex lesions differentially disrupt cocainereinforced conditioned place preference but not conditioned taste aversion. Behav Neurosci 103: 345-355.

Itzhak Y, Achat-Mendes C (2004). Methamphetamine and MDMA (Ecstasy) neurotoxicity: 'of mice and men'. IUBMB Life 56: 249-255.

Itzhak Y, Ali SF (1996). The neuronal nitric oxide synthase inhibitor, 7-nitroindazole, protects against methamphetamineinduced neurotoxicity in vivo. J Neurochem 67: 1770-1773.

Itzhak Y, Ali SF, Achat CN, Anderson KL (2003a). Relevance of MDMA ('ecstasy')-induced neurotoxicity to long-lasting psychomotor stimulation in mice. Psychopharmacology (Berl) 166: 241-248.

Itzhak Y, Ali SF, Anderson KL (2003b). Fenfluramine-induced serotonergic neurotoxicity in mice: lack of neuroprotection by inhibition/ablation of nNOS. J Neurochem 87: 268-271.

Itzhak Y, Gandia C, Huang PL, Ali SF (1998). Resistance of neuronal nitric oxide synthase-deficient mice to methamphetamine-induced dopaminergic neurotoxicity. J Pharmacol Exp Ther 284: 1040-1047.

Itzhak Y, Martin JL, Ali SF (2002). Methamphetamine-induced dopaminergic neurotoxicity in mice: long-lasting sensitization to the locomotor stimulation and desensitization to the rewarding effects of methamphetamine. Prog Neuropsychopharmacol Biol Psychiatry 26: 1177-1183.

Kita T, Wagner GC, Nakashima T (2003). Current research on methamphetamine-induced neurotoxicity: animal models of monoamine disruption. J Pharmacol Sci 92: 178-195.

Lyles J, Cadet JL (2003). Methylenedioxymethamphetamine (MDMA, Ecstasy) neurotoxicity: cellular and molecular mechanisms. Brain Res Brain Res Rev 42: 155-168.

Marston HM, Reid ME, Lawrence JA, Olverman HJ, Butcher SP (1999). Behavioural analysis of the acute and chronic effects of MDMA treatment in the rat. Psychopharmacology (Berl) 144: 67-76.

Martin JL, Itzhak Y (2000). 7-Nitroindazole blocks nicotineinduced conditioned place preference but not LiCl-induced conditioned place aversion. NeuroReport 11: 947-949.

McCann UD, Mertl M, Eligulashvili V, Ricaurte GA (1999). Cognitive performance in $( \pm$ ) 3,4-methylene-dioxymethamphetamine (MDMA, 'ecstasy') users: a controlled study. Psychopharmacology 143: 417-425.

McCann UD, Szabo Z, Scheffel U, Dannals RF, Ricaurte GA (1998). Positron emission tomographic evidence of toxic effect of MDMA ('Ecstasy') on brain serotonin neurons in human beings. Lancet 352: 1433-1437.

Miller DB, O'Callaghan JP (1994). Environment-, drug- and stressinduced alterations in body temperature affect the neurotoxicity of substituted amphetamines in the C57BL/6 $\mathrm{J}$ mouse. $J$ Pharmacol Exp Ther 270: 752-760.

National Research Council (1996). Guide for the Care and Use of Laboratory Animals. National Academy Press: Washington, DC. Olmstead MC, Franklin KB (1996). Differential effects of ventral striatal lesions on the conditioned place preference induced by morphine or amphetamine. Neuroscience 71: 701-708.

Packard MG, McGaugh JL (1996). Inactivation of hippocampus or caudate nucleus with lidocaine differentially affects expression of place and response learning. Neurobiol Learn Mem 65: 65-72.

Packard MG, Teather LA (1998). Amygdala modulation of multiple memory systems: hippocampus and caudate-putamen. Neurobiol Learn Mem 69: 163-203.

Parrott AC, Lees A, Garnham NJ, Jones M, Wesnes K (1998). Cognitive performance in recreational users of MDMA or 'ecstasy': evidence for memory deficits. J Psychopharmacol 12: 79-83.

Peat MA, Warren PF, Gibb JW (1983). Effects of a single dose of methamphetamine and iprindole on the serotonergic and dopaminergic system of the rat brain. J Pharmacol Exp Ther 225: $126-131$.

Pettit HO, Ettenberg A, Bloom FE, Koob GF (1984). Destruction of dopamine in the nucleus accumbens selectively attenuates cocaine but not heroin self-administration in rats. Psychopharmacology (Berl) 84: 167-173.

Phillips RG, LeDoux JE (1992). Differential contribution of amygdala and hippocampus to cued and contextual fear conditioning. Behav Neurosci 106: 274-285.

Reneman L, Lavalaye J, Schmand B, de Wolff FA, van den Brink W, den Heeten GJ et al (2001). Cortical serotonin transporter density and verbal memory in individuals who stopped using 3,4-methylenedioxymethamphetamine (MDMA or 'ecstasy'): preliminary findings. Arch Gen Psychiatry 58: 901-906.

Ricaurte GA, Markowska AL, Wenk GL, Hatzidimitriou G, Wlos J, Olton DS (1993). 3,4-Methylenedioxymethamphetamine, serotonin and memory. J Pharmacol Exp Ther 266: 1097-1105.

Roberts DC, Koob GF (1982). Disruption of cocaine selfadministration following 6-hydroxydopamine lesions of the ventral tegmental area in rats. Pharmacol Biochem Behav 17: 901-904.

Robinson TE, Castaneda E, Whishaw IQ (1993). Effects of cortical serotonin depletion induced by 3,4-methylenedioxymethamphe- 
tamine (MDMA) on behavior, before and after additional cholinergic blockade. Neuropsychopharmacology 8: 77-85.

Rogers RD, Everitt BJ, Baldacchino A, Blackshaw AJ, Swainson R, Wynne $\mathrm{K}$ et al (1999). Dissociable deficits in the decisionmaking cognition of chronic amphetamine abusers, opiate abusers, patients with focal damage to prefrontal cortex, and tryptophan-depeleted normal volunteers: evidence for monoaminergic mechanisms. Neuropsychopharmacology 20: 322-339.

Seiden LS, Sabol KE (1996). Methamphetamine and methylenedioxymethamphetamine neurotoxicty: possible mechanisms of cell destruction. NIDA Res Monogr 163: 251-276.

Sellings LH, Clarke PB (2003). Segregation of amphetamine reward and locomotor stimulation between nucleus accumbens medial shell and core. J Neurosci 23: 6295-6303.

Semple DM, Ebmeier KP, Glabus MF, O'Carroll RE, Johnstone EC (1999). Reduced in vivo binding to the serotonin transporter in the cerebral cortex of MDMA ('ecstasy') users. Br J Psychiatry 175: 63-69.

Simon SL, Domier C, Carnell J, Brethen P, Rawson R, Ling W (2000). Cognitive impairment in individuals currently using methamphetamine. Am J Addict 9: 222-231.

Stone DM, Hanson GR, Gibb JW (1987). Differences in the central serotonergic effects of methylenedioxymethamphetamine (MDMA) in mice and rats. Neuropharmacology 26: 1657-1661.

Strote J, Lee JE, Wechsler H (2002). Increasing MDMA use among college students: results of a national survey. J Adolesc Health 30: 64-72.
Effect of amphetamine neurotoxicity on Pavlovian conditioning C Achat-Mendes et al

Swanson LW, Petrovich GD (1998). What is the amygdala? Trends Neurosci 21: 323-331.

Taffe MA, Huitron-Resendiz S, Schroeder R, Parsons LH, Henriksen SJ, Gold LH (2003). MDMA exposure alters cognitive and electrophysiological sensitivity to rapid tryptophan depletion in rhesus monkeys. Pharmacol Biochem Behav 76: 141-152.

Thompson PM, Hayashi KM, Simon SL, Geaga JA, Hong MS, Sui Y et al (2004). Structural abnormalities in the brains of human subjects who use methamphetamine. J Neurosci 24: 6028-6036.

Verkes RJ, Gijsman HJ, Pieters MS, Schoemaker RC, de Visser S, Kuijpers $\mathrm{M}$ et al (2001). Cognitive performance and serotonergic function in users of ecstasy. Psychopharmacology (Berl) 153: 196-202.

Volkow ND, Chang L, Wang GJ, Fowler JS, Franceschi D, Sedler M et al (2001a). Loss of dopamine transporters in methamphetamine abusers recovers with protracted abstinence. J Neurosci 21: 9414-9418.

Volkow ND, Chang L, Wang GJ, Fowler JS, Leonido-Yee M, Franceschi D et al (2001b). Association of dopamine transporter reduction with psychomotor impairment in methamphetamine abusers. Am J Psychiatry 158: 377-382.

Vorhees CH, Inman-Wood SL, Morford LL, Broening HW, Fukumura M, Moran MS (2000). Adult learning deficits after neonatal exposure to D-methamphetamine: selective effects on spatial navigation and memory. J Neurosci 20: $4732-4739$. 